\title{
Coulisses
}

Revue de théâtre

3 | Hiver 1991

Théâtre et université

Theatre universitaire et théâtre antique

\section{Le théâtre universitaire de Nice nous a laissé sur notre faim... Antigone de sophocle}

\section{Rédaction}

\section{(2) OpenEdition}

Journals

Édition électronique

URL : http://journals.openedition.org/coulisses/1642

DOI : 10.4000/coulisses. 1642

ISSN : 2546-9460

Éditeur

Presses universitaires de Franche-Comté

Édition imprimée

Date de publication : 1 février 1991

Pagination : 35-37

ISSN : $1150-594 X$

Référence électronique

Rédaction, «Le théâtre universitaire de Nice nous a laissé sur notre faim... Antigone de sophocle », Coulisses [En ligne], 3 | Hiver 1991, mis en ligne le 04 juillet 2017, consulté le 23 octobre 2019. URL

http://journals.openedition.org/coulisses/1642; DOI : 10.4000/coulisses.1642

Ce document a été généré automatiquement le 23 octobre 2019

Coulisses 


\title{
Le théâtre universitaire de Nice
} nous a laissé sur notre faim... Antigone de sophocle

\author{
Rédaction
}

\section{Des conditions particulièrement favorables...}

1 Créé il y a une quinzaine d'années, le théâtre universitaire de Nice vit actuellement une période plutôt faste. Ses adhérents, de plus en plus nombreux, bénéficient désormais d'une salle très bien équipée (ce qui, bien souvent, fait défaut aux théâtres amateurs), mise à leur disposition par l'Université de Nice, lieu de répétition qui leur a permis de travailler dans des conditions particulièrement favorables et de produire trois spectacles : Antigone de Sophocle, présenté à Besançon dans le cadre des Rencontres internationales; le Père humilié de Paul Claudel, ainsi qu'une adaptation en comedia dell'arte du Discolos de Menandre, pièce antique du Iv ${ }^{\mathrm{e}}$ siècle avant Jésus Christ.

2 Si l'Université de Nice ne comporte pas, à l'inverse d'Aix-en-Provence par exemple de section théâtrale à proprement parler, le cursus des lettres modernes inclut de nombreuses unités de valeur de théâtre. En outre, les sections musicales et de danse, particulièrement réputées, entourent le Théâtre Universitaire qui baigne dans une environnement favorable, prouvant que, même s'il n'est pas institutionalisé dans le cadre des enseignements, l'univers du spectacle est fortement ancré dans la vie universitaire.

\section{... au service de la tragédie grecque}

3 Jouée à Besançon pour la huitième fois, Antigone appartient à ce que J. Lamiral, metteur en scène, animateur et fondateur de Théâtre universitaire de Nice, appelle « La Trilogie » de Sophocle. Helléniste et homme de théâtre, il a traduit, il y a quelques 
années, ๔Edipe roi, et compte achever son travail, avec đdipe à Colone; les trois pièces seront montées et présentées ensemble.

Monter une pièce classique représente un risque important, un travail conséquent... comment, en effet, éviter les éternels pièges posés par les nombreux metteurs en scène ayant proposé une interprétation sur la tragédie Grecque?

Nous n'avons pas l'intention de critiquer leur travail, affirme J. Lamiral, bien qu'ayant constitué l'occasion d'échanges et de découvertes, les Rencontres internationales ont également favorisé les confrontations et le développement d'un certain esprit critique chez les étudiants.

\section{Une carence quant à l'expression de l'émotion...}

Images solides et recherche esthétique certaine n'ont cependant par procuré l'émotion attendue. «Difficile de croire que cette Antigone là pouvait creuser la terre!» remarque un spectateur.

6 En outre, le chœur, si important dans la tragédie antique, puisque, continuellement pris à partie, il donne le mouvement et constitue une source d'énergie pour les autres, n'occupe malheureusement pas la place escomptée dans la mise en scène de J. Lamiral qui privilégie les principaux protagonistes, au détriment d'un choeur en retrait. Le Salut nous a d'ailleurs conforté dans notre impression: au choeur, aux figurants, ont succédé sur scène les " seconds rôles ", suivis enfin, par Antigone et Créon... s'agissait-il alors de mesurer leur popularité à l'applaudimètre? Le TU de Nice pronerait-il le vedettariat dans une conception hiérarchisée du théâtre?

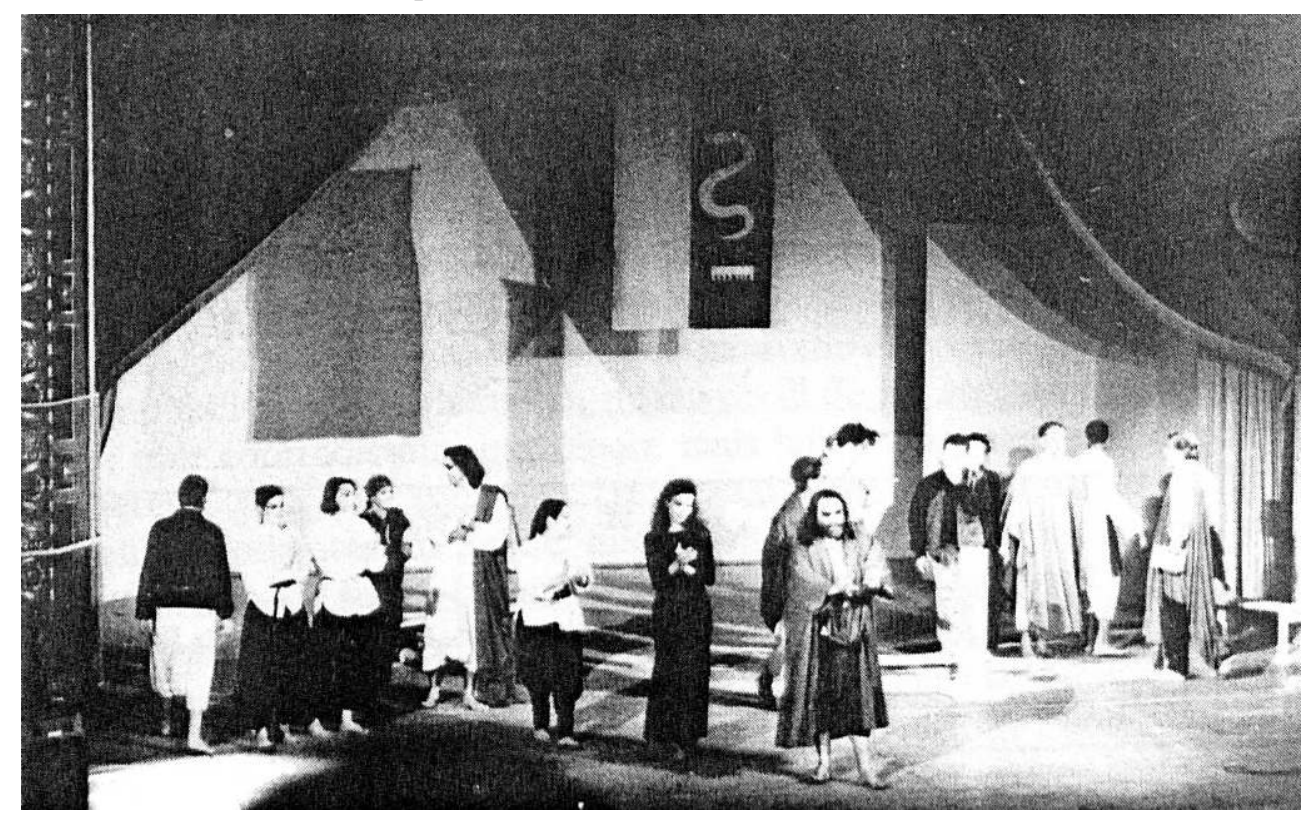




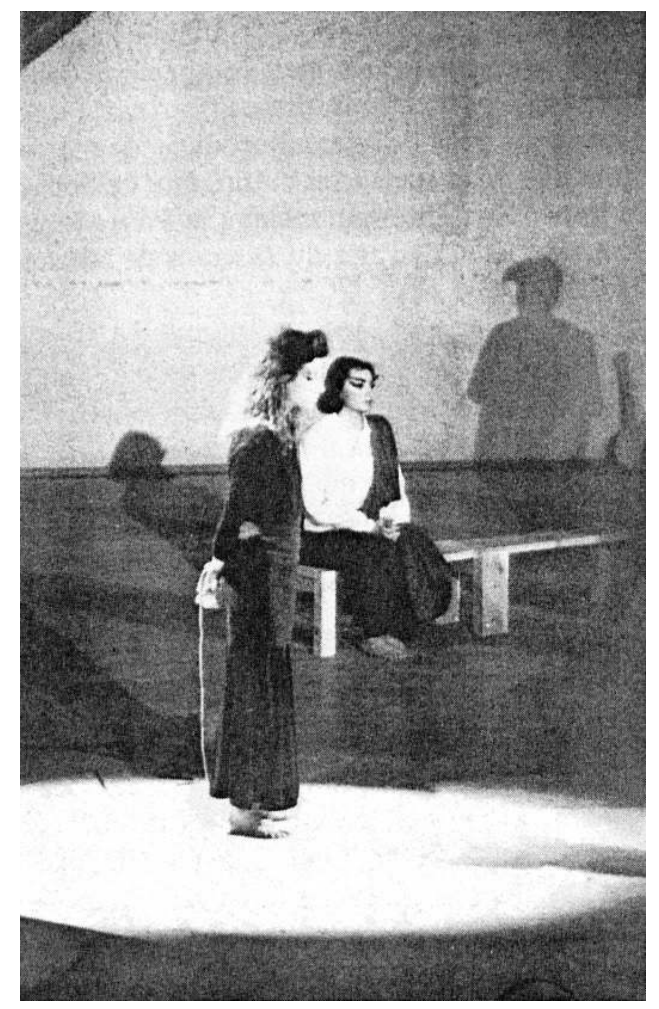

\section{... peut-être due à l'appréhension trop conventionnelle de la pièce}

L'apanage d'un TU réside, selon nous, dans la volonté de donner une partition égale à chacun, ou du moins, lorsque cela s'avère impossible, d'éviter au maximum, les mises en avant. Avant tout, le Théâtre universitaire réunit les étudiants dans le but d'une création commune au sein de laquelle les énergies individuelles se muent en énergie collective.

C'est en cela que le TU de Nice nous a déçu... spectacle traditionnel, conventionnel..., alors même que l'on s'attendrait à être surpris par quelque idée originale, quelque regard innovant sur cette pièce... Seule la Gitane, témoin et rapporteur de l'histoire d'Antigone, dans son chant aux consonances orientales, a répondu à cette attente. Convaincu que le propre d'un Théâtre universitaire est de travailler dans le sens d'une recherche collective, nous pensons que la tragédie antique, travaillée, remaniée, adaptée, jouée depuis des siècles constitue une source intarissable pour les metteurs en scène de tous temps, et laissait espérer une représentation moins conventionnelle. 